\title{
DETERMINATION OF RUTIN AND NARCISSIN IN MARIGOLD EXTRACT AND TOPICAL FORMULATIONS BY LIQUID CHROMATOGRAPHY: APPLICABILITY IN SKIN PENETRATION STUDIES
}

\author{
Yris Maria Fonseca, Fabiana T. M. C. Vicentini, Carolina Dias Catini e Maria José Vieira Fonseca* \\ Departamento de Ciências Farmacêuticas, Faculdade de Ciências Farmacêuticas de Ribeirão Preto, Universidade de São Paulo, \\ Av. do Café, s/n, 14040-903 Ribeirão Preto - SP, Brasil
}

Recebido em 9/10/09; aceito em 1/2//10; publicado na web em 6/5/10

\begin{abstract}
A chromatographic technique for determination of rutin and narcissin in marigold extract and topical formulations was developed and validated. The method shows linearity over the concentration range of $0.2-6.0 \mu \mathrm{g} / \mathrm{mL}$ of rutin $(\mathrm{r}=0.9986)$ and $0.8-12.0 \mu \mathrm{g} / \mathrm{mL}$ of $\operatorname{narcissin}(r=0.9951)$. The values obtained for precision and accuracy are in agreement with ICH guidelines. Both the formulation excipients and the porcine ear skin samples did not interfere with the flavonoids determination. The recovery of rutin and narcissin in skin samples added with marigold extract was $81.41 \%$ and $83.35 \%$, respectively, which demonstrate the applicability of this method to perform skin penetration studies.
\end{abstract}

Keywords: Calendula officinalis; narcissin; rutin.

\section{INTRODUCTION}

Calendula officinalis L. (Asteraceae) is an annual herb native to the Mediterranean region. In Europe and America it is cultivated for ornamental and medicinal purposes. It is commonly known as the marigold or maravilla, and its flowers have been applied in many medicinal preparations such as unguents, tinctures, dental gels, etc. ${ }^{1,2}$

Phytopharmacological studies of different marigold extracts have shown anti-viral, anti-HIV, ${ }^{3}$ anti-tumoral, ${ }^{4}$ anti-genotoxic ${ }^{5}$ and antioxidant activities..$^{6-8}$ In addition, marigold flowers have shown anti-inflammatory and wound healing properties. ${ }^{9-11}$ In clinical studies, marigold was highly efficacious in the prevention of acute dermatitis in cancer patients undergoing postoperative irradiation. ${ }^{12}$

Chemical constituents of Calendula officinalis include some triterpene saponins, triterpene alcohols, ${ }^{1}$ triterpene esters, ${ }^{13}$ carotenoi$\mathrm{ds},{ }^{14,15}$ flavonoids (quercetin, rutin, isorhamnetin and kaempferol), ${ }^{16}$ coumarins, essential oil, malic acid, mucilage, resin, tannin, sterols, among others. ${ }^{1,17}$

In recent years, there has been renewed interest in natural medicines that are obtained from plant parts or plant extracts. However, the idea that herbal drugs are safe and free from side effects is false. Plant extracts are biological materials and exhibit natural variations in composition, due to factors such as season, geography and cultivar that can greatly affect the quality and consequently the therapeutic value of herbal medicines. ${ }^{18}$ Therefore, it is very important to establish quality control parameters to insure their efficacy and safety.

The flavonoids, rutin and narcissin, were selected as chemical marker of marigold extract because flavonoids are a widespread group of natural products. Moreover, in recent years a lot of biochemical and pharmacological properties of vegetable extracts have been related to flavonoid content. ${ }^{19}$

In this study, a reverse phase- high performance liquid chromatography (RP-HPLC) technique for determination of rutin and narcissin in marigold extract was developed and validated. In addition, the applicability of this method in in vitro retention studies of topical formulations added with this extract was investigated. The results demonstrated that the developed method is a fast and reliable HPLC technique for determination of rutin and narcissin in topical

\footnotetext{
*e-mail: magika@fcfrp.usp.br
}

formulations added with marigold extract and to perform in vitro skin penetration studies.

\section{EXPERIMENTAL}

\section{Chemicals}

The Calendula officinalis L. dried flowers were a gift from Santos Flora (Sao Paulo, SP, Brazil). Rutin (95\%) was purchased from Sigma-Aldrich (St Louis, MO, USA). Narcissin (99\%) was purchased from Chromadex (Ivine, CA, USA). Acetic acid of chromatographic grade was supplied by Merck (Darmstadt, Germany). Acetonitrile $(\mathrm{ACN})$ and methyl alcohol $(\mathrm{MeOH})$ for use in chromatography and spectrophotometry were purchased from J. T. Baker (USA). The water used to prepare the solutions or mobile phase was purified in a Milli-Q-plus System (Millipore, Bedforte, MA, USA). Chloroform was supplied by Mallinckrodt Baker (Paris, France). Ethyl alcohol was supplied from Synth (Sao Paulo, Brazil). All the raw materials for the formulations were purchased from Galena (Campinas, SP, Brazil) or Clariant (Sao Paulo, SP, Brazil).

\section{Preparation of marigold extract}

The Calendula officinalis L. dried flowers were ground in a knife mill into fine particles $(0.3 \mathrm{~mm}$ - mean diameter). The powdered drug was macerated with $50 \%$ ethanol $(1: 9, \mathrm{w} / \mathrm{w})$ at $25^{\circ} \mathrm{C}$ for 5 days. This mixture was submitted to mechanical stirring at $870 \mathrm{rpm}$ (Fisatom, model $713 \mathrm{D}$ ) for $1 \mathrm{~h}$ at the beginning and end of the maceration period. Afterwards, the extract was filtered and dried at $40{ }^{\circ} \mathrm{C}$ in a stove with air circulation. Finally, the residue was dissolved into $50 \%$ hydroalcoholic solution $(200 \mathrm{~mL})$ and stored at $-20{ }^{\circ} \mathrm{C}$. The extract obtained by this procedure presented $15.7 \%$ dry weight.

\section{Determination of rutin and narcissin by HPLC}

\section{Apparatus and chromatographic conditions}

The rutin and narcissin levels in marigold extract were determined using a Shimadzu (Kyoto, Japan) liquid chromatograph system equipped with an LC-10 AT VP solvent pump unit and an SPD-10A VP UV-Visible detector operating at $340 \mathrm{~nm}$. Samples 
were injected manually through a rheodyne injector (20 $\mu \mathrm{L}$ loop). Separation was performed in a BDS Hypersyl C18 column $(250 \mathrm{x}$ $4.6 \mathrm{~mm}, 5 \mu \mathrm{m}$ ) (Part. ${ }^{\circ}$ 28105-254630) (Thermo electron corporation, USA), equipped with a precolumn BDS Hypersyl C18 (10 x 4 $\mathrm{mm}, 5 \mu \mathrm{m})$ (Thermo electron corporation, USA). The mobile phase was acetonitrile-water $(15: 85, \mathrm{v} / \mathrm{v})$ containing $2 \%(\mathrm{v} / \mathrm{v})$ acetic acid at a flow rate of $1 \mathrm{~mL} / \mathrm{min}$. Data were collected using a chromatopac C-R6A integrator (Shimadzu, Kyoto, Japan).

\section{Validation}

Validation was performed following the ICH guidelines. ${ }^{20}$ The method was validated considering the parameters linearity, accuracy, precision, limit of detection and limit of quantitation.

Linearity was checked with standard solutions of rutin in the concentration range of $0.2-6.0 \mu \mathrm{g} / \mathrm{mL}$ and narcissin in the concentration range of $0.8-12.0 \mu \mathrm{g} / \mathrm{mL}$. The standard curves were analyzed by linear regression of peak area versus narcissin or rutin concentration.

Precision was expressed as relative standard deviation (RSD \%) and was determined by repeatability (intra-day) and intermediate precision (inter-day). Repeatability was evaluated by analysis of six replicates in the same day under the same experimental conditions. The intermediate precision was studied by assaying 6 replicates on 3 different days.

The accuracy experiments applied the standard addition method (rutin and narcissin) in the sample (marigold extract), using replicates $(n=3)$ of three different rutin and narcissin concentrations.

For that, the marigold extract solution was prepared by dilution of $100 \mu \mathrm{L}$ of concentrated extract $(15.7 \%$ dry weight) into $10 \mathrm{~mL}$ of $50 \%$ methanolic solution. Next, $8 \mathrm{~mL}$ of this solution were diluted into $25 \mathrm{~mL}$ of mobile phase, being detected a final rutin concentration of $0.91 \mu \mathrm{g} / \mathrm{mL}$. This Marigold extract solution $(5 \mathrm{~mL})$ was spiked with three different volumes (1,2 and $3 \mathrm{~mL})$ of rutin standard solution $(2.0$ $\mu \mathrm{g} / \mathrm{mL})$ and diluted once more $(10 \mathrm{~mL})$, obtaining rutin theoretical final concentrations of $0.66,0.86$ and $1.06 \mu \mathrm{g} / \mathrm{mL}$.

In the accuracy experiments of narcissin content, the marigold extract solution was prepared by dilution of $100 \mu \mathrm{L}$ of concentrated extract into $10 \mathrm{~mL}$ of $50 \%$ methanolic solution $(18.3 \mu \mathrm{g} / \mathrm{mL})$. Next, $500 \mu \mathrm{L}$ of this solution and $0.6,1.0$ and $1.4 \mathrm{~mL}$ narcissin standard solution $(10 \mu \mathrm{g} / \mathrm{mL})$ were diluted into $5 \mathrm{~mL}$ of mobile phase. Then, narcissin theoretical final concentrations obtained in each solution were of 3.04, 3.84 and $4.64 \mu \mathrm{g} / \mathrm{mL}$.

Finally, the solutions were filtered and analyzed by the developed HPLC method. Accuracy was expressed as percent of recovery, which was estimated as the relation between the experimental concentrations and the theoretical concentrations $\left(\left(\mathrm{C}_{\mathrm{e}} / \mathrm{C}_{\mathrm{t}}\right) \times 100\right)$.

The detection limit (LD) and quantitation limit (LQ) were determined on the basis of the standard deviation of the response and the slope of the constructed calibration curve. The LD was expressed as $(3.3 \times) / S$ and, the LQ was expressed as $(10 \times) / S$, where is the standard deviation of the response and $S$ is the slope of calibration curve.

\section{Method application}

\section{Formulations}

Topical formulations were developed using two different selfemulsifying agents and one polymer, as it can be seen in Table 1 . Formulation 1 (gel-cream) was prepared using the self-emulsifying agent Hostacerin $\mathrm{SAF}^{\circledR}$ and formulation 2 (cream) using the commercially available self-emulsifying wax Polawax ${ }^{\circledR}$, isodecyl oleate and isopropyl palmitate as emollient and glycerol as a moisturizer. The preservatives used for F1 and F2 were a mixture of phenoxyethanol and parabens, previously dissolved in propylene glycol and then incorporated into the formulations at room temperature. Formulation
3 (gel) was prepared using the nonionic polymer Natrosol 250HHR ${ }^{\circledR}$, hyaluronic acid as a moisturizer and polyoxyethylene (20) sorbitan monolaurate and ethyl alcohol as co-solvent. The preservative used for F3 was DMDM hydantoin (1,3-Dimethylol-5,5-dimethylhydantoin glydant), previously dissolved in propylene glycol and then incorporated into the formulations at room temperature. Water was replaced for Mcllvaine buffer ( $0.2 \mathrm{M}$ disodium hydrogen phosphate and $0.1 \mathrm{M}$ citric acid, $\mathrm{pH}$ 6.0) in the preparation of all formulations. Marigold extract $(5 \%, \mathrm{w} / \mathrm{w})$ was incorporated to the formulations at room temperature, $24 \mathrm{~h}$ after its preparation. Control formulations were prepared without the extract $(\mathrm{C} 1, \mathrm{C} 2$ and $\mathrm{C} 3)$.

Table 1. Percent composition (w/w) of the formulations

\begin{tabular}{|c|c|c|c|c|c|c|}
\hline Components & F 1 & $\mathrm{~F} 2$ & F3 & $\mathrm{C} 1$ & $\mathrm{C} 2$ & $\mathrm{C} 3$ \\
\hline$\overline{\text { Hostacerin SAF}}{ }^{\oplus a}$ & 6 & - & - & 6 & - & - \\
\hline Polawax ${ }^{\oplus b}$ & - & 8 & - & - & 8 & - \\
\hline Natrosol 250HHR ${ }^{\circledR c}$ & - & - & 1.5 & - & - & 1.5 \\
\hline Isodecyl oleate & - & 2 & - & - & 2 & - \\
\hline Isopropyl palmitate & - & 1.5 & - & - & 1.5 & - \\
\hline Glycerol & - & 3 & - & - & 3 & - \\
\hline Phenoxyethanol and parabens & 0.5 & 0.5 & - & 0.5 & 0.5 & - \\
\hline DMDM hydantoin $^{\mathrm{d}}$ & - & - & 0.4 & - & - & 0.4 \\
\hline Propylene glycol & 5 & 5 & 10 & 5 & 5 & 10 \\
\hline Ethanol & - & - & 30 & - & - & 30 \\
\hline $\begin{array}{l}\text { Polyoxyethylene (20) sorbitan } \\
\text { monolaurate }\end{array}$ & - & - & 1 & - & - & 1 \\
\hline Hyaluronic acid $1 \%$ & - & - & 1 & - & - & 1 \\
\hline Mcllvaine buffer & 88.5 & 80 & 56.1 & 88.5 & 80 & 56.1 \\
\hline Marigold extract & 5 & 5 & 5 & - & - & - \\
\hline
\end{tabular}

a Self-emulsifying was prepared without heating (ammonium acryloyldimethyl-taurate/VP copolymer+rapessed oil sorbitol esters+trilauril-4 phosphate+mineral oil+isopropyl palmitate); ${ }^{b}$ self-emulsifing wax (alcohol cetoesteariliric and sorbitan monostearate $20 \mathrm{OE}$ ); ${ }^{c}$ polymer nonionic (ultrahigh-molecular-weight hydroxyethylcellulose); ${ }^{\mathrm{d}}$ 1,3-Dimethylol-5,5dimethylhydantoin glydant; ${ }^{\mathrm{e}} 0.2 \mathrm{M}$ disodium hydrogen phosphate and 0.1 $\mathrm{M}$ citric acid, $\mathrm{pH}$ 6.0.

\section{Rutin and narcissin content in marigold extract and topical formulations}

The developed method was used for determination of rutin and narcissin content in marigold extract and topical formulations.

For that, marigold extract solutions were prepared by dilution of $100 \mu \mathrm{L}$ of concentrated extract into $10 \mathrm{~mL}$ of $50 \%$ methanolic solution. Next, $1 \mathrm{~mL}$ of this solution was diluted into $5 \mathrm{~mL}$ of mobile phase. Finally, this solution was filtered and analyzed by HPLC.

Formulation samples were diluted into $50 \%$ hydroalcoholic solution $(1: 9, \mathrm{w} / \mathrm{w})$. Then, $2 \mathrm{~mL}$ of this solution were added to $2 \mathrm{~mL}$ of chloroform. This mixture was submitted to mechanical stirring $\left(\mathrm{Ika}^{\circledR}\right.$ works, model MS 1) at $2500 \mathrm{rpm}$ for $1 \mathrm{~min}$ and centrifuged (Excelsa Baby I, model 206-R) at $3000 \mathrm{rpm}$ for $10 \mathrm{~min}$. $400 \mu \mathrm{L}$ of aqueous phase were diluted in $600 \mu \mathrm{L}$ of mobile phase, filtered and analyzed by HPLC.

\section{Rutin and narcissin recovery in pig skin samples}

Known concentrations of the marigold extract were applied to the skin and further submitted to the extraction procedure, as described by Wagner and collaborators, ${ }^{21}$ who evaluated the recovery of sesquiterpene lactones in skin retention study.

Then, to conduct this study the skin from the outer surface of an excised porcine ear was used. Pig ears were obtained within $2 \mathrm{~h}$ after slaughter of the animals. The whole skin membrane was then carefully removed from the underlying cartilage with the help of a 
scalpel. The subcutaneous tissues were removed and the skin stored at $-20{ }^{\circ} \mathrm{C}$ for a maximum period of 30 days before use. ${ }^{22}$

Firstly, skin sections (area of $1.77 \mathrm{~cm}^{2}$ ) were subjected to tape stripping to remove the stratum corneum (SC) from the remaining epidermis (E) and dermis (D) $[\mathrm{E}+\mathrm{D}]$. For this procedure, 15 tapes were successive stripped (invisible tape) on the skin sections. Secondly, the remaining $[\mathrm{E}+\mathrm{D}]$ was added with the same concentration of marigold extract present in $500 \mathrm{mg}$ of formulation $(25 \mu \mathrm{L})$. Then, this skin sections were cut in small pieces, homogenized in 50\% methanolic solution $(2 \mathrm{~mL})$ using turratec homogeneitor (Tecnal, model TE-102) at $20500 \mathrm{rpm}$ for $2 \mathrm{~min}$. This mixture was led to ultra-sound for $15 \mathrm{~min}$, mixed in vortex (Phoenix, model AP56) for $1 \mathrm{~min}$, and centrifuged for $15 \mathrm{~min}$ at $1660 \mathrm{~g}$. After the centrifugation, the supernatant was filtered $(0.45 \mu \mathrm{m}$ filter, Millipore, Brazil) and placing it in a second test-tube. The supernatant was evaporated to dryness under air-flow and reconstituted into $50 \%$ methanolic solution $(500 \mu \mathrm{L})$. Then, $100 \mu \mathrm{L}$ of this solution were diluted in $400 \mu \mathrm{L}$ of mobile phase, filtered and analyzed by HPLC, as described above.

The same procedure was done by skin samples without previous addition of Marigold extract in order to evaluate if the skin constituents might interfere with rutin and narcissin detection by the developed method using HPLC.

The absolute recovery of rutin and narcissin extracted from skin layers was determined considering the Equation below:

$$
\text { Recovery }(\%)=\frac{\mathrm{Ce}}{\mathrm{Ci}} \times 100
$$

where, $\mathrm{Ce}=$ represents the experimental concentration of rutin or narcissin obtained after extraction procedure and $\mathrm{Ci}=$ represents the initial concentration of rutin or narcissin present in marigold extract added to the skin before the extraction procedure.

\section{RESULTS AND DISCUSSION}

In the present work, RP-HPLC with UV detection and isocratic mobile phase mode was proposed as a suitable method for quantitative determination of rutin and narcissin in marigold extract (Figure 1). In addition, the applicability of this method in in vitro retention studies of topical formulations added with this extract was suggested.<smiles>[R9]OC1C(O)C2C(=CC(O)CC2O)OC1C1CC([R])C(O)C([R2])C1</smiles>

$$
\begin{array}{ll}
\text { Rutin } & \text { Narcissin } \\
& \\
\mathrm{R}_{1}=\mathrm{H} & \mathrm{R}_{1}=\mathrm{OCH}_{3} \\
\mathrm{R}_{2}=\mathrm{OH} & \mathrm{R}_{2}=\mathrm{H} \\
\mathrm{R}_{3}=\text { rutinose } & \mathrm{R}_{3}=\text { rutinose }
\end{array}
$$

Figure 1. Structures of the rutin and narcissin

The chromatographic analysis developed for quantitative determination of these flavonoids was validated according to ICH guidelines,${ }^{20}$ to obtain reproducible analyses with high degree of accuracy and precision in the range of concentrations investigated.

Under the experimental conditions, the linearity was maintained within the concentration range considered. A regression analysis was performed, with the observation of the good linearity and the representative linear equation was $y=15100 x-1746$ for rutin and $y=20390 x+477.3$ for narcissin. Table 2 summarizes the results of the regression analysis and shows the slope, intercept and correlation coefficient for each calibration range. The correlation coefficients for all the calibration curves were all close to 0.99 .

Table 2. Linearity of rutin and narcissin in the HPLC analysis

\begin{tabular}{lcccc}
\hline & $\begin{array}{c}\text { Concentration } \\
\text { range }(\mu \mathrm{g} / \mathrm{mL})\end{array}$ & Slope & Intercept & $r$ \\
\hline Rutin & $0.2-6.0$ & $15100 \pm 197.3$ & $-1746 \pm 560.3$ & 0.9986 \\
Narcissin & $0.8-12.0$ & $20390 \pm 475.4$ & $477.3 \pm 2948$ & 0.9951 \\
\hline
\end{tabular}

The results are mean \pm SD of three experiments; $r$ - Correlation coefficient.

The repeatability and intermediate precision were determined by performing 6 replicate analyses of the extract samples and evaluated by RSD of the peak area of rutin or narcissin. The mean of peak area, rutin or narcissin content and the relative standard deviation are reported in Table 3.

Table 3. Precision of HPLC method for quantitation of rutin and narcissin in marigold extract

\begin{tabular}{lcccc}
\hline & Peak area & $\begin{array}{c}\text { RSD } \\
(\%)\end{array}$ & $\begin{array}{c}\text { Rutin } \\
(\mu \mathrm{g} / \mathrm{mL})\end{array}$ & $\begin{array}{c}\text { RSD } \\
(\%)\end{array}$ \\
Intra-day precision $^{\mathrm{a}}$ & $5819 \pm 293.36$ & 5.04 & $237.21 \pm 10.40$ & 4.38 \\
Inter-day precision $^{\mathrm{b}}$ & $5998 \pm 231.18$ & 3.85 & $236.27 \pm 6.45$ & 2.73 \\
\hline & Peak area & $\begin{array}{c}\text { RSD } \\
(\%)\end{array}$ & $\begin{array}{c}\text { Narcissin } \\
(\mu \mathrm{g} / \mathrm{mL})\end{array}$ & $\begin{array}{c}\text { RSD } \\
(\%)\end{array}$ \\
& & 2.77 & $1860 \pm 50.0$ & 2.78 \\
Intra-day precision $^{\mathrm{a}}$ & $75862 \pm 2102$ & 2.37 & $1830 \pm 70.0$ & 3.65 \\
Inter-day precision $^{\mathrm{b}}$ & $72847 \pm 3909$ & 5.37 &
\end{tabular}

The results are mean \pm SD of 6 determinations. ${ }^{\text {a }} 6$ replicates were assayed on the same day; ${ }^{\mathrm{b}} 6$ replicates were assayed on 3 different days.

The accuracy of the method was determined by adding known amount of rutin and narcissin standard in known marigold extract samples at 3 levels of concentration. The mean values of the percentage analytical recoveries for the concentration of $0.66,0.86$ and 1.06 $\mu \mathrm{g} / \mathrm{mL}$ of rutin were $97.98,100$ and $103.46 \%$, respectively. The mean values of the percentage analytical recoveries for the concentration of $3.04,3.84$ and $4.64 \mu \mathrm{g} / \mathrm{mL}$ of narcissin were $90.46,95.83$ and $103.45 \%$, respectively (Table 4 ).

Table 4. Accurancy of the HPLC method

\begin{tabular}{cccc}
\hline & $\begin{array}{c}\text { Rutin added } \\
(\mu \mathrm{g} / \mathrm{mL})\end{array}$ & $\begin{array}{c}\text { Rutin found } \\
(\mu \mathrm{g} / \mathrm{mL})\end{array}$ & $\begin{array}{c}\text { Recovery } \\
(\%)\end{array}$ \\
$\mathrm{A}$ & 0.66 & $0.65 \pm 0.01$ & $97.98 \pm 0.87$ \\
$\mathrm{~B}$ & 0.86 & $0.86 \pm 0.01$ & $100.00 \pm 1.16$ \\
$\mathrm{C}$ & 1.06 & $1.09 \pm 0.02$ & $103.46 \pm 1.44$ \\
\hline & Narcissin added & Narcissin found & Recovery \\
& $(\mu \mathrm{g} / \mathrm{mL})$ & $(\mu \mathrm{g} / \mathrm{mL})$ & $(\%)$ \\
$\mathrm{A}$ & 3.04 & $2.75 \pm 0.44$ & $90.46 \pm 14.96$ \\
$\mathrm{~B}$ & 3.84 & $3.68 \pm 0.21$ & $95.83 \pm 5.88$ \\
$\mathrm{C}$ & 4.64 & $4.80 \pm 0.53$ & $103.45 \pm 11.44$ \\
\hline
\end{tabular}

A - Low concentration, B - intermediate concentration and C - high concentration for range calibration. The results are mean \pm SD of 3 experiments.

The values obtained for precision and accuracy determination are in agreement with accepted validation produced, which indicates that the chromatographic conditions used is reliable to quantify both flavonoids in the range evaluated.

The detection limit of rutin and narcissin were 0.12 and $0.48 \mu \mathrm{g} /$ $\mathrm{mL}$, respectively and the quantitation limit of rutin and narcissin were 0.37 and $1.45 \mu \mathrm{g} / \mathrm{mL}$, respectively. 
The applicability of this method for determination of rutin and narcissin in topical formulations added with marigold extract was also investigated. For that, blank samples of formulations (C1, C2 and C3) were evaluated in relation to the chromatographic characteristics (peaks presence and retention time). The blank samples of formulations did not show any interference regards to the chromatographic characteristics (data not shown). In the presence of excipients, the chromatographic profiles of rutin, narcissin and others compounds (retention time and area) were not affected. Figure 2 shows the chromatogram of topical formulations added with marigold extract and the extract alone.
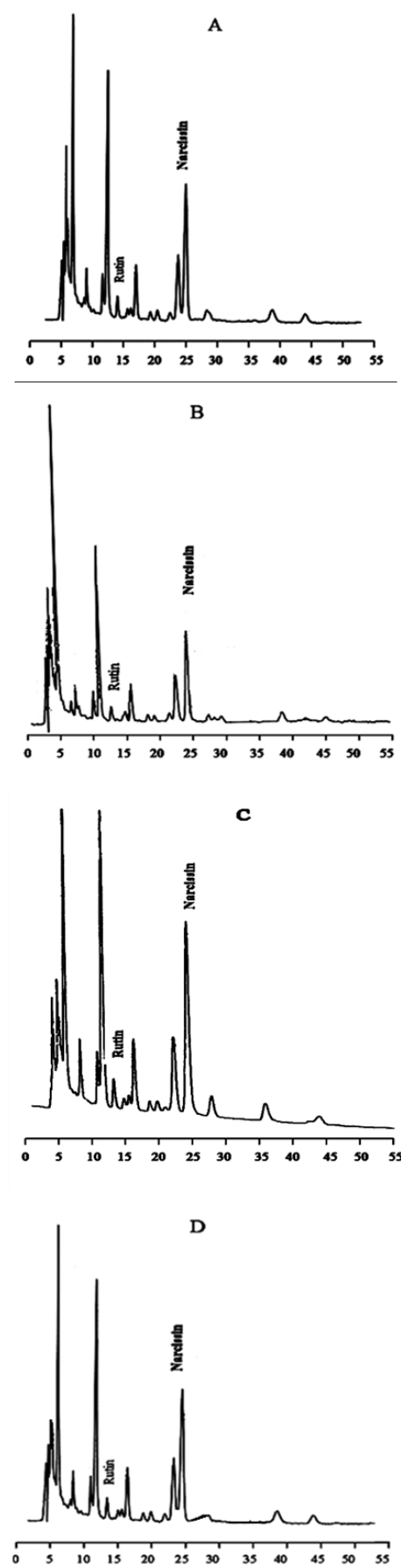

Figure 2. Typical chromatogram of marigold extract and topical formulations added with marigold extract. A: marigold extract, B: F 1, C: $F 2$ and D: F 3

The recovery of rutin in formulations added with marigold extract, as showed in Table 5, were 103.4, 92.32 and $81.60 \%$ for F1, F2 and F3, respectively. The recoveries of narcissin in formulations added with marigold extract were $92.95,109.05$ and $108.15 \%$ for F1, F2 and F3, respectively. Therefore, the proposed method was specific and selective for rutin and narcissin incorporated in these formulations once the formulations components caused no interference with the rutin and narcissin determination. Besides this, the developed HPLC methodology could be used to perform the quality control of these three different formulations added with marigold extract.

Table 5. Rutin and narcissin concentration in marigold extract and recovery in topical formulations added with this extract

\begin{tabular}{lccc}
\hline $\begin{array}{l}\text { Rutin } \\
(\mu \mathrm{g} / \mathrm{g})\end{array}$ & $\begin{array}{c}\text { Concentration } \\
\text { added }\end{array}$ & $\begin{array}{c}\text { Concentration } \\
\text { found }\end{array}$ & $\begin{array}{c}\text { Recovery } \\
(\%)\end{array}$ \\
F 1 & 12.50 & $12.88 \pm 0.73$ & 103.04 \\
F 2 & 12.50 & $11.54 \pm 1.00$ & 92.32 \\
F 3 & 12.50 & $10.20 \pm 0.81$ & 81.60 \\
Extract & - & $239.0 \pm 13.2$ & - \\
$(\mu \mathrm{g} / \mathrm{g})$ & Concentration & Concentration & Recovery \\
\hline Narcissin & added & found & $(\%)$ \\
$(\mu \mathrm{g} / \mathrm{g})$ & 95.67 & $88.93 \pm 16.9$ & 92.95 \\
F 1 & 95.67 & $104.32 \pm 11.8$ & 109.05 \\
F 2 & 95.67 & $103.47 \pm 6.3$ & 108.15 \\
F 3 & & $1910 \pm 70.0$ & - \\
Extract & - & & \\
$(\mu \mathrm{g} / \mathrm{g})$ & & & \\
\hline
\end{tabular}

The results are mean $(n=3) \pm$ Std. Error of 3 experiments.

In the evaluation of the applicability of this method for determination of rutin and narcissin in skin samples, it was observed that chromatographic profiles of rutin, narcissin and others compounds (retention time and area) were not affected by the biological matrices (Figure 3 ). In addition, the recovery of rutin in skin samples added to marigold extract was $81.41 \%$ and narcissin was $83.35 \%$ (Table 6 ). Therefore, the combined procedures for extraction and HPLC assay of rutin and narcissin in skin samples is efficient in terms of recovery and fast manipulation.

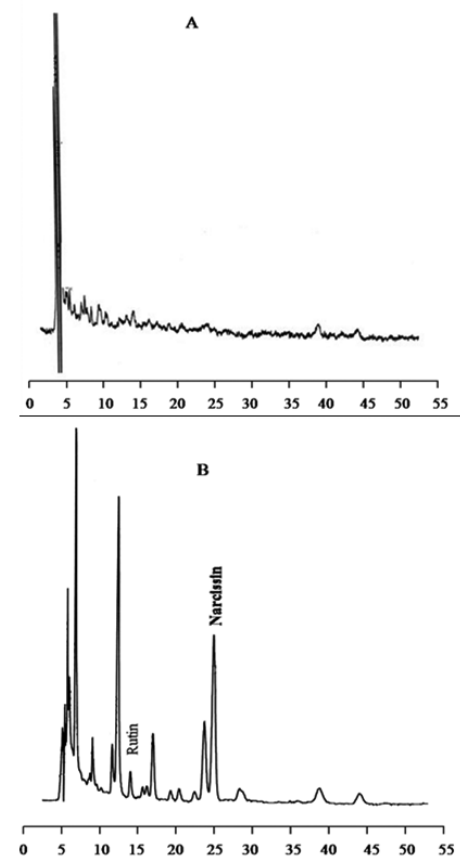

Figure 3. Recovery of rutin and narcissin extracted from skin layers. A: skin sample without marigold extract and B: skin sample with marigold extract 
Table 6. Recovery of rutin and narcissin extracted from skin layers

\begin{tabular}{lcc}
\hline & Rutin & Narcissin \\
\hline Concentration added $(\mu \mathrm{g})^{\mathrm{a}}$ & 7.12 & 45.90 \\
Concentration found $(\mu \mathrm{g})$ & $5.80 \pm 0.50$ & $38.26 \pm 0.78$ \\
Recovery $(\%)$ & $81.41 \pm 6.97$ & $83.35 \pm 1.69$ \\
\hline
\end{tabular}

${ }^{\text {a }}$ Rutin and narcissin concentration in $25 \mu \mathrm{L}$ of marigold extract added to skin samples. The results are mean \pm SD of 3 experiments.

The extraction procedures accomplished for preparation of the samples in studies of recovery in topical formulations and skin samples do not significantly affect the recovery of rutin and narcissin. These extraction procedures showed to be effective for determination of both flavonoids in biological and pharmaceutical matrices.

\section{CONCLUSION}

Concluding, the present work developed a fast and reliable HPLC technique for determination of rutin and narcissin in topical formulations added with marigold extract. Moreover, the high recovery of rutin and narcissin from porcine ear skin samples demonstrate that the method reported could successfully be applied in in vitro skin penetration studies of topical formulations added with this extract.

\section{ACKNOWLEDGMENTS}

The authors are grateful to Coordenação de Aperfeiçoamento de Pessoal de Nível Superior (CAPES); Conselho Nacional de Desenvolvimento Científico e Tecnológico (CNPq) and Fundação de Amparo à Pesquisa do Estado de São Paulo (FAPESP) for financial support and for granting a research fellowship.

\section{REFERENCES}

1. Re, T. A.; Mooney, D.; Antignac, E.; Dufour, E.; Bark, I.; Srinivasan, V.; Nohynek, G.; Food Chem. Toxicol. 2009, 47, 1246.

2. Duke, J. A.; Bogenschutz-Godwin, M. J.; Du Celliar, J.; Duke, P. A. K.; Hand Book of Medicinal Herbs, $2^{\text {nd }}$ ed., CRC Press: Boca Raton, 2002.
3. Kalvatchev, Z.; Walder, R.; Garzaro, D.; Biomed. Pharmacother. 1997, $51,176$.

4. Jiménez-Medina, E.; Garcia-Lora, A.; Paco, L.; Algarra, I.; Collado, A.; Garrido, F.; BMC câncer 2006, 6, 1 .

5. Pérez-Carreón, J. I.; Cruz-Jiménez, G.; Licea-Vega, J. A.; Popoca, E. A.; Fazenda, S. F.; Villa-Treviño, S.; Toxicology 2002, 16, 253.

6. Cordova, C. A. S.; Siqueira, I. R.; Netto, C. A.; Yunes, R. A.; Volpato, A. M.; Filho, V. C.; Curi-Predrosa, R.; Creczynski-Pasa, T. B.; Redox Rep. 2002, 7, 95

7. Ćetković, G. S.; Djilas, S. M.; Čanadanović-Brunet, J. M.; Tumbas, V. T.; Food Res. Int. 2004, 37, 643.

8. Katalinic, V.; Milos, M.; Kulisic, T.; Jukic, M.; Food Chem. 2006, 94, 550.

9. Della-Loggia, R.; Tubaro, A.; Sosa, S.; Becker, H.; Saar, S.; Isaac, O.; Planta Med. 1994, 60, 516.

10. Zitterl-Eglseer, K.; Sosa, S.; Jurenitsch, J.; Schubert-Zssilavecz, M.; Della Loggia, R.; Tubaro, A.; Bertoldi, M.; Franz, C.; J. Ethnopharmacol. 1997, 57, 139.

11. Fronza, M.; Heinzmann, B.; Hamburger, M.; Laufer, S.; Merfort, I.; J. Ethnopharmacol. 2009, 126, 463.

12. Pommier, P.; Gomez, F.; Sunyach, M. P.; D’Hombres, A.; Carrie, C.; Montbarbon, X.; J.C.O. 2004, 22, 1447.

13. Neukirch, H.; D’Ambrosio, M.; Dalla-Via, J.; Guerreiro, A.; Phytochem. Anal. 2004, 15, 30.

14. Bakó, E.; Deli, J.; Tóth,G.; J. Biochem. Biophys. Methods 2002, 53, 241.

15. Kishimoto, S.; Maoka, T.; Simitomo, K.; Ohmiya, A.; Biosci., Biotechnol., Biochem. 2005, 69, 2121.

16. Pietta, P.; Mauri, P.; Rava, A.; J. Chromatogr. 1992, 593, 165.

17. Hamburgeer, M.; Adler, S.; Baumann, D.; Forg, A.; Weinreich, B.; Fitoterapia 2003, 74, 328 .

18. Calixto, J. B.; Braz. J. Med. Biol. Res. 2000, 33, 179.

19. Kaefer, C. M.; Milner, J. A.; J. Nutr. Biochem. 2008, 19, 347.

20. International Conference on Harmonization ( $\mathrm{ICH}$ ), ICH Harmonized tripartite guideline, Topic Q2B; Note for guidelines on Validation of Analytical Procedures: Methodology, 1996.

21. Wagner, S.; Merfort, I.; J. Pharm. Biomed. Anal. 2007, 43, 32.

22. Casagrande, R.; Georgetti, S. R.; Verri Jr, W. A.; Borin, M. F.; Lopez, R. F. V.; Fonseca, M. J. V.; Int. J. Pharm. 2007, 328, 183. 